\title{
Distinguishing between acute and subacute massive pulmonary embolism by conventional and Doppler echocardiography
}

Wolfgang Kasper, Annette Geibel, Nikolaus Tiede, Dirk Bassenge, Elisabeth Kauder, Stavros Konstantinides, Thomas Meinertz, Hanjörg Just

\begin{abstract}
Objective-To determine the ability of conventional and Doppler echocardiography to distinguish between minor, acute massive, and subacute massive pulmonary embolism in patients with confirmed pulmonary embolism.

Design-Prospective study of a consecutive series of 47 patients with confirmed pulmonary embolism.
\end{abstract}

Setting-Department of internal medicine, university clinic.

Patients-11 patients (23\%) had minor, 23 patients $(49 \%)$ had acute massive, and 13 patients $(28 \%)$ had subacute massive pulmonary embolism.

Results-Dilatation of the right ventricular cavity (33 (92\%)) and asynergy of the right ventricular free wall (29 (81\%)) were seen only in patients with acute and subacute massive pulmonary embolism $(\mathbf{n}=36) .23(64 \%)$ with pulmonary hypertension had tricuspid regurgitation. The velocity of the tricuspid regurgitant jet correlated with the pulmonary arterial pressure $(r=0.88$, SEE $=11.6 \mathrm{~mm} \mathrm{Hg})$ and was significantly lower in patients with acute massive pulmonary embolism $(3.0(0.4) \mathrm{m} / \mathrm{s}, \mathbf{n}=12)$ than in patients with subacute massive pulmonary embolism (4.2 (0.6) $\mathrm{m} / \mathrm{s} ; n=11)(p<$ $0.001)$. The use of predefined indices (right ventricular free wall thickness $>5 \mathrm{~mm}$; tricuspid regurgitant jet velocity $>3.7 \mathrm{~m} / \mathrm{s}$; and the occurrence of both $a$ dilated right ventricular cavity with normal interventricular septal motion, or an inspiratory collapse of the inferior vena cava, or both) correctly identified 11 of 13 patients $(85 \%)$ with subacute massive pulmonary embolism.

Conclusion-Conventional and Doppler echocardiography were successful in evaluating the haemodynamic consequences of pulmonary embolism.

(Br Heart f 1993;70:352-356)

Pulmonary embolism is rarely an isolated event and symptoms can often be traced back over several days to weeks. The term subacute massive pulmonary embolism refers to recurrent thromboembolic events resulting in severe pulmonary arterial hypertension over 6-8 weeks. $^{1}$ Patients with recurrent pulmonary embolism are poorly identified by clinical findings and cannot be distinguished by non-invasive measurements from those with acute massive pulmonary embolism. ${ }^{12}$

Several studies have examined the accuracy of echocardiography in diagnosing the haemodynamic consequences of acute pulmonary embolism. ${ }^{3}$ We examined the ability of Doppler-echocardiographic findings to distinguish between patients with acute massive pulmonary embolism from those with subacute massive pulmonary embolism.

\section{Patients and methods}

We prospectively studied 363 patients who presented at our institution between March 1987 and December 1989 with clinical evidence of pulmonary embolism and who were treated on the medical and surgical wards as emergency patients and as inpatients. A final diagnosis of pulmonary embolism was established in $164(45 \%)$. In 47 (29\%) (32 men and 15 women mean (ISD) age 55 (18) years) pulmonary embolism was confirmed by pulmonary angiography $(n=44(94 \%)$ or by a typical ventilation-perfusion lung scan and precapillary pulmonary hypertension $(n=3(6 \%)$.

Those with normal pulmonary arterial pressure were diagnosed as having minor pulmonary embolism. Patients with pulmonary hypertension (defined as an increase in mean pulmonary arterial pressure of $>20 \mathrm{~mm} \mathrm{Hg}$ at rest) were considered to have acute massive pulmonary embolism. Subacute massive pulmonary embolism was defined as a mean pulmonary arterial pressure of $>40 \mathrm{~mm} \mathrm{Hg}$ or systolic pulmonary arterial pressure of $>70 \mathrm{~mm} \mathrm{Hg}$ or both. ${ }^{12}$ Patients in whom the first clinical symptoms of suspected pulmonary embolism started $>8$ weeks before presentation were excluded.

\section{RIGHT HEART CATHETERISATION}

A Swan-Ganz catheter was introduced to measure right sided pressures and cardiac output and total pulmonary vascular resistance was calculated according to the following equation: Pulmonary vascular resistance $=$ mean pulmonary arterial pressure/cardiac output $\times 80$ (dyn.s. $\left.\mathrm{cm}^{-5}\right)$.

Bilateral pulmonary cineangiograms were obtained with a Berman catheter in 41/47 patients (87\%) after the injection of $30-40 \mathrm{ml}$ Urografin at a flow rate of $15-19 \mathrm{ml} / \mathrm{s}$ and a film speed of 25 frames in the anterior-posterior right lung and left anterior oblique left lung projections. Pulmonary angiograms were evaluated by the Miller score. ${ }^{4}$ 
Pulmonary embolism was confirmed by digital subtraction angiography in three patients $(6 \%)$. A ventilation/perfusion scan was recorded in $28 / 47$ patients $(60 \%)$. Inhalation studies were performed with ${ }^{99 m} \mathrm{Tc} /$ macroaggregated albumin followed by perfusion scans with intravenously administered ${ }^{99 m} \mathrm{Tc}$-diethylenetriamine pentaacetic acid in the anterior, posterior, and lateral projections.

Conventional and Doppler echocardiographic examinations were performed with a Toshiba SSH 160 A echocardiograph interfaced with a 3.75 and $2.5 \mathrm{MHz}$ transducer. An integrated continuous wave Doppler flow was used for measurements. The patients were studied from the apical, parasternal, subcostal, and suprasternal views. The following echocardiographic indices were determined:

\section{CROSS SECTIONAL AND M MODE INDICES}

End diastolic left and right ventricular diameters and the end systolic left ventricular diameter were determined from a parasternal short axis view by the leading edge method. Left ventricular dilatation was defined as an end diastolic diameter of $>56 \mathrm{~mm} . .^{5}$ Dilatation of the right ventricle was considered to be present when the right ventricular cavity area was at least the size of the left ventricular cavity area in an apical or subcostal four chamber view or when the right ventricular end diastolic diameter was $>30 \mathrm{~mm} .{ }^{16}$ The motion of the right ventricular free wall was evaluated by an apical or subcostal four chamber view and classified as normal or asynergic. Right ventricular hypertrophy was defined as a wall thickness $>5 \mathrm{~mm}$ determined from a parasternal short axis or subcostal view. ${ }^{67}$

Left ventricular function was estimated from the $\mathrm{E}$ point septal separation during early diastole in the parasternal short axis view ( $<7 \mathrm{~mm}=$ normal)..$^{8}$ The movement of the interventricular septum was qualitatively classified as normal, hypokinetic, or paradoxical. The right pulmonary artery was measured from the suprasternal view. ${ }^{910}$ Dilatation of the right pulmonary artery was defined as an end diastolic lumen diameter of $\geqslant 12 \mathrm{~mm} / \mathrm{m}^{2}$ body surface. ${ }^{3}$ Variation of the lumen of the inferior vena cava during inspiration was evaluated from a subcostal view. ${ }^{112}$ Inspiratory collapse of the inferior vena cava (defined as decrease of the lumen diameter of $>50 \%$ from the maximal

Table 1 Haemodynamic findings in patients with pulmonary embolism (mean (SD))

\begin{tabular}{|c|c|c|c|c|c|}
\hline & $\begin{array}{l}\text { Acute minor } \\
(n=11)\end{array}$ & $\stackrel{p}{\text { Value }}$ & $\begin{array}{l}\text { Acute massive } \\
(n=23)\end{array}$ & $\stackrel{p}{\text { Value }}$ & $\begin{array}{l}\text { Subacute } \\
\text { massive } \\
(n=13)\end{array}$ \\
\hline 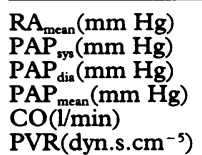 & $\begin{array}{r}1.5(0.9) \\
21.1(5.9) \\
5.9(3.1) \\
11.0(3.5) \\
8.5(3.2) \\
114(34)\end{array}$ & $\begin{array}{l}\mathrm{p}<0.001 \\
\mathrm{p}<0.001 \\
\mathrm{p}<0.001 \\
\mathrm{p}<0.001 \\
\mathrm{p}<0.01 \\
\mathrm{p}<0.001\end{array}$ & $\begin{array}{r}8 \cdot 2(5 \cdot 7) \\
40 \cdot 8(7 \cdot 3) \\
15 \cdot 9(7 \cdot 1) \\
24 \cdot 1(4 \cdot 6) \\
4 \cdot 7(1 \cdot 6) \\
460(185)\end{array}$ & $\begin{array}{l}\text { NS } \\
\mathrm{p}<0.001 \\
\mathrm{p}<0.01 \\
\mathrm{p}<0.001 \\
\mathrm{NS} \\
\mathrm{p}<0.001\end{array}$ & $\begin{array}{c}9 \cdot 7(7 \cdot 2) \\
84 \cdot 7(18 \cdot 4) \\
30 \cdot 2(15 \cdot 4) \\
49 \cdot 5(15 \cdot 6) \\
4 \cdot 4(1 \cdot 9) \\
1100(613)\end{array}$ \\
\hline
\end{tabular}

$\mathrm{RA}_{\text {men }}$, mean right atrial pressure; $\mathrm{PAP}_{\mathrm{sp}}$ systolic pulmonary arterial pressure; $\mathbf{P A P}_{\text {dia }}$ diastolic pulmonary arterial pressure; $P A P_{\text {menn }}$ mean pulmonary arterial pressure; $\mathrm{CO}$, cardiac output; pulmonary arterial pressure; $P A P$ mean
met total pulmonary vascular resistance. diameter at end expiration) was assumed to indicate a right atrial mean pressure of $4 \mathrm{~mm}$ $\mathrm{Hg}$. If there was no inspiratory collapse the right atrial pressure was estimated to be $12 \mathrm{~mm} \mathrm{Hg}$.

\section{DOPPLER MEASUREMENTS}

Colour-coded or continuous wave Doppler studies or both were used to evaluate tricuspid regurgitation. The maximal flow velocity of the tricuspid regurgitant jet was determined by continuous wave Doppler. The pressure gradient was calculated according to the simplified Bernoulli equation. ${ }^{13} 14$

The presence of one of the following echocardiographic or Doppler criteria was taken as evidence for the presence of pulmonary hypertension:

- Right ventricular wall thickness $>5 \mathrm{~mm}$

- Tricuspid regurgitant jet velocity $>2.5$ $\mathrm{m} / \mathrm{s}$ (25 $\mathrm{mm} \mathrm{Hg}$ ) without inspiratory collapse of the inferior vena cava and/or with paradoxical motion of the interventricular septum

- Dilatation of the right ventricular cavity and dilatation of the right pulmonary artery

In patients with pulmonary hypertension, subacute massive pulmonary embolism was defined prospectively by Doppler echocardiographic indices when one of the following criteria was fulfilled:

- Right ventricular wall thickness $>5 \mathrm{~mm}$

- Tricuspid regurgitant jet velocity $>3 \cdot 7$ $\mathrm{m} / \mathrm{s}$

- Dilatation of the right ventricular cavity with either collapse of the inferior vena cava and/or normal motion of the interventricular septum.

\section{STATISTICAL ANALYSIS}

Data with a normal distribution were described as mean (SD). Differences between indices were analysed by an unpaired Student's $t$ test, $\chi^{2}$ test, or Fisher's exact test. The relation of catheter and Doppler gradients was assessed by linear regression analysis with Pearson's correlation coefficient.

\section{Results}

HAEMODYNAMIC FINDINGS

On the basis of haemodynamic findings (table 1) 11 (23\%) patients had pulmonary embolism without pulmonary hypertension and 36 patients $(77 \%)$ had pulmonary embolism with pulmonary hypertension. In the patients with pulmonary hypertension, acute massive pulmonary embolism was diagnosed in 23 patients (49\%) and subacute massive pulmonary embolism in 13 patients (28\%). Patients with subacute massive pulmonary embolism $(n=13)$ had significantly higher pulmonary arterial pressure and higher pulmonary vascular resistance than patients with acute massive pulmonary embolism.

ECHOCARDIOGRAPHIC AND DOPPLER FINDINGS Pulmonary embolism without pulmonary hypertension caused neither dilatation of the 
Table 2 Echocardiographic and Doppler indices

\begin{tabular}{|c|c|c|c|}
\hline & $\begin{array}{l}P E \text { without } P H \\
(n=11)\end{array}$ & p Value & $\begin{array}{l}P E \text { with } P H \\
(n=36)\end{array}$ \\
\hline \multicolumn{4}{|c|}{ Cross sectional indices } \\
\hline $\begin{array}{l}\text { RVILV ratio: } \\
\text { RV } \geqslant L V \\
\text { RV }<L V\end{array}$ & $\overline{11}(100 \%)$ & $\begin{array}{l}<0.01 \\
<0.001\end{array}$ & $\begin{array}{c}33(92 \%) \\
3(8 \%)\end{array}$ \\
\hline $\begin{array}{l}R V \text { wall motion: } \\
\text { Normal } \\
\text { Hypokinetic }\end{array}$ & $11(100 \%)$ & $\begin{array}{l}<0.01 \\
<0.01\end{array}$ & $\begin{array}{r}7(19 \%) \\
29(81 \%)\end{array}$ \\
\hline $\begin{array}{l}\text { IVC collapes: } \\
\text { Present } \\
\text { Absent }\end{array}$ & $-8(72 \%)$ & $\begin{array}{l}\text { NS } \\
<0.01\end{array}$ & $\begin{array}{l}10(28 \%) \\
21(58 \%)\end{array}$ \\
\hline $\begin{array}{l}\text { IVS motion: } \\
\text { Normal } \\
\text { Hypokinetic } \\
\text { Paradoxical }\end{array}$ & $\begin{array}{l}11(100 \%) \\
- \\
-\end{array}$ & $\begin{array}{l}<0.001 \\
\text { NS } \\
<0.01\end{array}$ & $\begin{array}{r}6(17 \%) \\
5(14 \%) \\
24(67 \%)\end{array}$ \\
\hline \multicolumn{4}{|c|}{\begin{tabular}{rcr} 
& $M$ mode indices \\
$4.1(0.6)(\mathrm{n}=8)$ & $<0.05$ \\
$25.8(4.5)(\mathrm{n}=9)$ & $<0.001$ \\
$13.2(2.4)(\mathrm{n}=9)$ & $<0.001$ \\
$47.0(7.1)(\mathrm{n}=9)$ & $<0.001$ \\
$20.3(3.4)(\mathrm{n}=10)$ & $<0.01$ \\
$10.8(1.4)(\mathrm{n}=10)$ & $<0.001$ \\
& \multicolumn{2}{c}{ Doterler indices }
\end{tabular}} \\
\hline $\begin{array}{l}\text { Vmax (RV/RA, m/s) } \\
\text { DP (RV/RA, mm Hg) } \\
\text { DPc (RV/RA, mm Hg) }\end{array}$ & Doppler & ndices & $\begin{array}{c}3 \cdot 6(0 \cdot 8)(n=23) \\
54 \cdot 1(23 \cdot 8)(n=23) \\
63 \cdot 2(24 \cdot 4)(n=23)\end{array}$ \\
\hline
\end{tabular}

$\mathrm{PE}$, pulmonary embolism; $\mathrm{PH}$, pulmonary hypertension; $\mathrm{RV}$, right ventricle, $\mathrm{LV}$, left ventricle; IVC, inferior vena cava; IVS, interventricular septum; RVWT, right ventricular wall thickness, RVEDD(I), right ventricular end diastolic diameter (index); RPA(I), right pulmonary artery (index); Vmax, maximal flow velocity; DP(c), maximal pressure gradient ( $c=$ corrected in relation to the mean atrial pressure).

Correlation between Doppler-derived systolic pulmonary arterial pressure and the invasive

measurements. PAP, pulmonary arterial pressure.

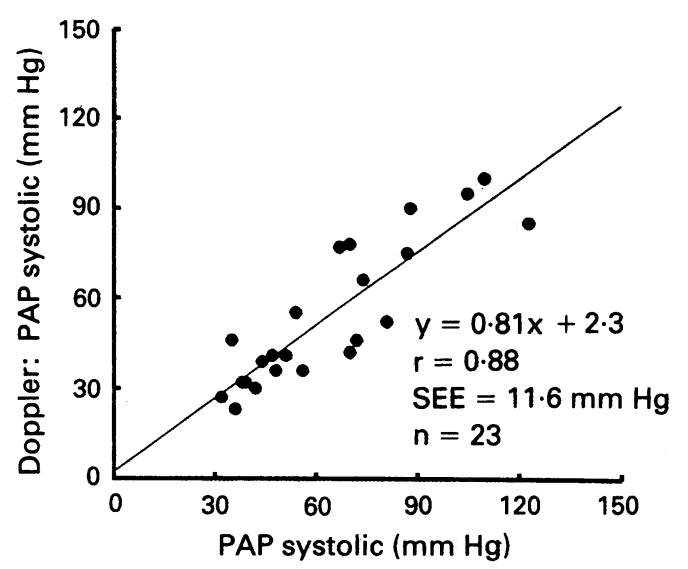

Table 3 Differentiation between acute and subacute massive pulmonary embolism

\begin{tabular}{|c|c|c|c|}
\hline & $\begin{array}{l}\text { Acute } \\
(n=23)\end{array}$ & p Value & $\begin{array}{l}\text { Subacute } \\
(n=13)\end{array}$ \\
\hline \multicolumn{4}{|c|}{ Cross sectional indices: } \\
\hline $\begin{array}{l}\text { RV/LV ratio: } \\
\mathrm{RV} \geqslant \mathrm{LV} \\
\mathrm{RV}<\mathrm{LV}\end{array}$ & $\begin{array}{r}21(91 \%) \\
2(9 \%) .\end{array}$ & $\begin{array}{l}\text { NS } \\
\text { NS }\end{array}$ & $\begin{array}{c}12(92 \%) \\
1(8 \%)\end{array}$ \\
\hline $\begin{array}{l}R V \text { wall motion: } \\
\text { Normal } \\
\text { Hypokinetic }\end{array}$ & $\begin{array}{r}4(17 \%) \\
19(83 \%)\end{array}$ & $\begin{array}{l}\text { NS } \\
\text { NS }\end{array}$ & $\begin{array}{r}3(23 \%) \\
10(77 \%)\end{array}$ \\
\hline $\begin{array}{l}\text { IVC collapse: } \\
\text { Present } \\
\text { Absent }\end{array}$ & $\begin{array}{r}6(26 \%) \\
13(57 \%)\end{array}$ & $\begin{array}{l}\text { NS } \\
\text { NS }\end{array}$ & $\begin{array}{l}4(31 \%) \\
8(62 \%)\end{array}$ \\
\hline $\begin{array}{l}\text { IVS motion: } \\
\text { Normal } \\
\text { Hypokinetic } \\
\text { Paradoxical }\end{array}$ & $\begin{array}{l}2(9 \%) \\
3(13 \%) \\
17(74 \%)\end{array}$ & $\begin{array}{l}\text { NS } \\
\text { NS } \\
\text { NS }\end{array}$ & $\begin{array}{l}4(31 \%) \\
2(15 \%) \\
7(54 \%)\end{array}$ \\
\hline $\begin{array}{l}\operatorname{RVWT}(\mathrm{mm}) \\
\operatorname{RVEDD}(\mathrm{mm}) \\
\operatorname{RVEDDI}\left(\mathrm{mm} / \mathrm{m}^{2}\right) \\
\text { LVEDD }(\mathrm{mm}) \\
\operatorname{RPA}(\mathrm{mm}) \\
\operatorname{RPAI}\left(\mathrm{mm} / \mathrm{m}^{2}\right)\end{array}$ & $\begin{array}{c}\text { M mode indices } \\
4 \cdot 4(0 \cdot 6)(\mathrm{n}=18) \\
34 \cdot 1(6 \cdot 9)(\mathrm{n}=20) \\
19 \cdot 0(3 \cdot 8)(\mathrm{n}=20) \\
38 \cdot 7(4 \cdot 8)(\mathrm{n}=21) \\
25 \cdot 2(4 \cdot 5)(\mathrm{n}=23) \\
14 \cdot 0(2 \cdot 6)(\mathrm{n}=23) \\
\text { Doppler indices }\end{array}$ & $\begin{array}{l}\mathrm{p}<0.05 \\
\text { NS } \\
\text { NS } \\
\text { NS } \\
\text { NS } \\
\text { NS }\end{array}$ & $\begin{array}{l}5 \cdot 4(1 \cdot 3)(n=10) \\
34 \cdot 2(4 \cdot 8)(n=13) \\
18.5(2.5)(n=13) \\
41.4(5 \cdot 9)(n=11) \\
25.0(3.7)(n=12) \\
13.9(2.5)(n=12)\end{array}$ \\
\hline $\begin{array}{l}\text { Vmax (RV/RA, m/s) } \\
\text { DP (RV/RA, mm Hg) } \\
\text { DPc (RV/RA, mm Hg) }\end{array}$ & $\begin{array}{c}3.0(0 \cdot 4)(n=12) \\
36 \cdot 6(8 \cdot 7)(n=12) \\
45 \cdot 3(7 \cdot 3)(n=12)\end{array}$ & $\begin{array}{l}<0.001 \\
<0.01 \\
<0.001\end{array}$ & $\begin{array}{r}4 \cdot 2(0.59)(\mathrm{n}=11) \\
72 \cdot 4(21 \cdot 1)(\mathrm{n}=11) \\
81 \cdot 8(22 \cdot 5)(\mathrm{n}=11)\end{array}$ \\
\hline
\end{tabular}

PE, pulmonary embolism; RV, right ventricle, LV, left ventricle; IVC, inferior vena cava; IVS, interventricular septum; RVWT, right ventricular wall thickness; RVEDD(I), right ventricular end diastolic diameter (index); RPA(I), right pulmonary artery (index); Vmax, maximal flow velocity; DP $(c)$, maximal pressure gradient ( $=$ corrected in relation to mean atrial pressure). right ventricle nor impairment of right ventricular free wall motion (table 2). In contrast, dilatation of the right ventricle was seen in 33 patients $(92 \%)$ with pulmonary hypertension and asynergy of the right ventricular free wall was seen in 29 patients $(81 \%)$.

Motion of the interventricular septum was normal in all patients without pulmonary hypertension: 24 patients $(67 \%)$ with pulmonary hypertension had paradoxical septal wall motion. The absence of inspiratory collapse of the inferor vena cava was only seen in patients with pulmonary hypertension. Tricuspid regurgitation was not detected in any patient without pulmonary hypertension. In contrast, it was found in 23 patients (64\%) with pulmonary hypertension.

\section{DIAGNOSIS AND MEASUREMENT OF}

PULMONARY HYPERTENSION

A close correlation was found between systolic pulmonary arterial pressure measured at catheterisation and systolic pressure estimated by Doppler examinations (figure). Pulmonary hypertension was diagnosed by Doppler echocardiographic indices in 34/36 patients $(94 \%)$. Six $(17 \%)$ had right ventricular hypertrophy, 22 patients $(61 \%)$ had a tricuspid regurgitant jet velocity $>2.5 \mathrm{~m} / \mathrm{s}$ with either absence of inspiratory collapse of the inferior vena cava or paradoxical motion of the interventricular septum, and 26 patients (72\%) had a dilatation of the right ventricle and the right pulmonary artery. In two patients none of the Doppler and echocardiographic criteria could be evaluated. None of the patients with pulmonary embolism and normal pulmonary pressure by catheterisation fulfilled any of the Doppler echocardiographic criteria for pulmonary hypertension.

\section{DISTINCTION BETWEEN ACUTE AND SUBACUTE} MASSIVE PULMONARY EMBOLISM

Table 3 shows the echocardiographic and Doppler measurements in patients with pulmonary hypertension with acute or subacute massive pulmonary embolism. Patients with acute pulmonary embolism had a thinner right ventricular free wall than those with subacute massive pulmonary embolism. Predefined echocardiographic criteria for subacute massive pulmonary embolism were fulfilled in $11 / 13$ patients ( $85 \%$ ). A right ventricular wall thickness $>5 \mathrm{~mm}$ was seen in five patients, a tricuspid regurgitant jet velocity $>3.7 \mathrm{~m} / \mathrm{s}$ in nine, and a right ventricular dilatation in the presence of an inspiratory collapse of the inferior vena cava in three. None of the 23 patients with acute massive pulmonary embolism fulfilled any of the above criteria.

\section{Discussion}

Haemodynamically significant pulmonary embolism causes characteristic echocardiographic changes in patients without previous cardiopulmonary disease. ${ }^{3}$ Dilatation of the right ventricle and central pulmonary vessels reflects pressure stress on the pulmonary cir- 
culatory system. ${ }^{9}$ The absence of collapse of the inferior vena cava during inspiration seems to be a sign of right heart failure. ${ }^{112}$ Paradoxical motion of the interventricular septum is often seen. If left ventricular disease can be ruled out, these findings usually indicate haemodynamically important pulmonary embolism. ${ }^{15}$

The clinical course of pulmonary embolism is so diverse that the evaluation of the presence, severity, or duration of the disease is often not possible without additional invasive examinations. Pulmonary hypertension with a mean pulmonary arterial pressure $>40 \mathrm{~mm}$ $\mathrm{Hg}$ or an increase in the total pulmonary resistance by $>800$ dyn.s. $\mathrm{cm}^{-5}$ indicates that the disease has been present for some time. ${ }^{2}$ Earlier studies described the relation between echocardiographic changes and the angiographic severity of pulmonary embolism. ${ }^{1516}$ But they did not distinguish between acute or subacute massive pulmonary embolism.

\section{ECHOCARDIOGRAPHIC CHANGES IN PULMONARY EMBOLISM}

The reported frequency of right ventricular dilatation confirmed echocardiographically in patients with pulmonary embolism ranges from $50 \%-100 \% .{ }^{17-20}$ Seventy per cent of our patients with pulmonary embolism and $92 \%$ of patients with pulmonary embolism and pulmonary hypertension had right ventricular dilatation.

Come et al described impaired motion of the right ventricular free wall in seven patients with haemodynamically significant pulmonary embolism..$^{18} \mathrm{We}$ found asynergy in $81 \%$ of patients with pulmonary hypertension but in no patient without raised pressure in the pulmonary circulatory system.

Kasper et al detected paradoxical septal wall motion by echocardiography in $80-100 \%$ of patients with pulmonary embolism. ${ }^{3}$ We found it in only those with pulmonary hypertension, and less commonly in patients with subacute massive pulmonary embolism (54\%) than in those with acute massive pulmonary embolism (74\%).

Dilatation of the right pulmonary artery was present in $26 / 36$ patients ( $72 \%$ ) with pulmonary hypertension and in $1 / 11$ patients $(10 \%)$ without raised pressure in the pulmonary circulatory system.

Normally, the inferior vena cava collapses during forced inspiration. If it does not this indicates high pressure in the right atrium. ${ }^{1112}$ In this study the absence of inspiratory collapse of the inferior vena cava was found only in patients with pulmonary hypertension.

\section{DOPPLER EXAMINATIONS IN PATIENTS WITH} PULMONARY EMBOLISM

When there is no obstruction of the right ventricular outflow tract measurement of the tricuspid regurgitant jet velocity permits estimation of systolic pulmonary arterial pressure. ${ }^{21}$ In other studies the reported frequency of tricuspid regurgitation detected by Doppler examination in patients with chronic pulmonary hypertension was $46-90 \%$. Come et al were the first to report the use of this method in patients with acute pulmonary embolism. They used it to estimate rightsided pressure in $5 / 7$ patients. ${ }^{18}$ Chapoutot et al found tricuspid regurgitation in $36 / 39$ patients (92\%) with pulmonary embolism by Doppler echocardiography and made a fairly accurate estimate of pulmonary arterial pressure. ${ }^{16}$ In our study we found tricuspid regurgitation in only $23 / 47$ patients (49\%): however, the rate among patients with pulmonary hypertension was $64 \%$. The low detection rate for tricuspid regurgitation may have been the result of the studies being performed during the acute state of the disease, generally at the bedside. None the less, the correlation was good between the systolic pulmonary arterial pressure estimated by Doppler and the value obtained invasively. A regurgitant jet velocity of $>3.5 \mathrm{~m} / \mathrm{s}$ at the tricuspid valve was considered by Metz et al to be a sign of a chronic pressure increase in the pulmonary circulatory system..$^{22}$ We found that a tricuspid regurgitant jet velocity of $>3.7 \mathrm{~m} / \mathrm{s}$ together with other echocardiographic indices such as the presence of right ventricular hypertrophy or right ventricular cavity dilatation, and absence of the collapse of the inferior vena cava during inspiration, identified $85 \%$ of patients with subacute massive pulmonary embolism.

We found that in patients with pulmonary embolism Doppler echocardiographic indices allowed the haemodynamic relevance of pulmonary embolism to be ascertained. Pulmonary hypertension in patients with pulmonary embolism correlated with changes in the right heart and the right pulmonary artery shown by echocardiography and was associated with a raised regurgitant jet velocity over the triscuspid valve. Furthermore, in patients with haemodynamically significant pulmonary embolism, echocardiographic and Doppler findings distinguished between acute and subacute massive pulmonary embolism, which may help to guide further management

NT is a recipient of a grant from the Sandoz foundation for therapeutic research, Erlangen. SK is a recipient of a grant from the Deutsche Akademische Auslandsdienst, Bonn.

1 Sutton GC, Hall RJC, Kerr IH. Clinical course and late prognosis of treated subacute massive, acute minor, and
chronic pulmonary thromboembolism. Br Heart $\mathcal{F} 1977$; 39:1135-42.

2 McIntyre KM, Sasahara AA. The hemodynamic and ventricular response to pulmonary embolism. Prog Cardiovasc Dis 1974;17:175-90

3 Kasper W, Geibel A, Tiede N, Hofmann T, Meinertz T, Just H. Echocardiographic diagnosis of pulmonary embolism. Herz 1989;14:82-101.

4 Miller GAH, Sutton GC. Acute massive pulmonary embolism. Clinical and haemodynamic findings in 23 patients studied by cardiac catherization and pulmonary arteriography. Br Heart f 1970;32:518-23. Ecigenbaum H. Echocardiography. 4th ed. Philadelphia: Lea \& Febiger, 1986;622.

6 Foale $R$, Nihoyannopoulos $P$, McKenna $W$, et al. Echocardiographic measurement of the normal adult right ventricle. $B r$ Heart $\mathcal{F} 1986 ; 56: 33-4$.

7 atsukubo $\mathrm{H}$, Matsuura T, Endo $\mathrm{N}$, et al. Echocardiographic measurement of right ventricular wall thickness: A new application of subxiphoid echocardiography. Circulation 1977;56:278-84.

8 Massie BM, Schiller NB, Ratshin RA, Parmley WW. Mitral-septal separation: New echo cardiographic index of left ventricular function. Am $\mathcal{f}$ Cardiol 1977;39: 1008-16. 
9 Kasper $W$, Meinertz T, Kersting F, Löllgen H, Limburg $P$, Just $H$. Echocardiography in assessing acute pulmonary hypertension due to pulmonary embolism. Am $\mathcal{f}$ Cardiol 1980;45:567-72.

10 Kasper W, Meinertz T, Kersting F, Löllgen H, Just H. Wall motion characteristics of the right pulmonary artery in the suprasternal echocardiogram ff Clin Ultrasound 1980;8:201-6.

11 Moreno FLL, Hagan AD, Holmen JR, Pryor TA, Strickel $\mathrm{RD}$, Castle $\mathrm{CH}$. Evaluation of size and dynamics of the $\mathrm{RD}$, Castle $\mathrm{CH}$. Evaluation of size and dynamics of the
inferior vena cava as an index of the right sided cardiac inferior vena cava as an index of the right
function. Am $₹$ Cardiol 1984;53:579-85.

12 Simonson JS, Schiller NB. Sonospirometry: A new method for noninvasive estimation of mean right atrial pressure based on two-dimensional echographic measurements of the inferior vena cava during measured inspiration. I Am Coll Cardiol 1988;11:557-64.

13 Currie PJ, Seward JP, Chan KL. Continuous wave Doppler determination of right ventricular pressure: A
simultaneous Doppler-catheterization study in 127 patients. F Am Coll Cardiol 1985;6:750-6.

14 Skjaerpe T, Hatle L. Noninvasive estimation of systolic pressure in the right ventricle in patients with tricuspid pressure in the right ventricle in patients
regurgitation. Eur Heart $\mathcal{f} 1986 ; 7: 704-10$.

15 Kasper W, Meinertz T, Henkel B, et al. Echocardiographic findings in patients with proved pulmonary embolism. Am Hear f 1986;112:1284-90.

16 Chapoutot L, Metz D, Jolly D, et al. Diagnostic, prognostic and therapeutic value of Doppler echocardiography in pulmonary embolism. Apropos 41 cases. Ann Cardiol Angeiol 1989;38:523-29.
17 Jardin F, Dubois O, Guéret P, Delorme G, Bourdarias JP. Quantitative two-dimensional echocardiography in massive pulmonary embolism: Emphasis on ventricular interdependence and leftward septal displacement. $\mathcal{F} \mathrm{Am}$ Coll Cardiol 1987;10:1201-6.

18 Come PC, Kim D, Parker JA, Goldhaber SZ, Braunwald E, Markis JE and participating investigators. Early reversal of right ventricular dysfunction in patients with acute pulmonary embolism after treatment with intravenous tissue plasminogen activator. $\mathcal{f} \mathrm{Am}$ Coll Cardiol venous tissue plasm

19 Bocherau G, Scheuble C, Cereze $P$, Chanveau $P$, Jounitzky D, Kleinknecht $D$. Intérêt de l'echocardiographie dans le diagnostic d'un coeur pulmonaire aigue. A propos de 6 observations. Agressologie 1980;21:112-17.

20 Castillo-Fenoy A, Scheuble A, Benacerraf A, Braun J Cereze P. Semeiologie echocardiographique de l'embolie pulmonaire aigue. Arch Mal Coeur 1980;73:971-8.

21 Yock PG, Popp RL. Noninvasive estimation of right ventricular systolic pressure by Doppler ultrasound in patients with tricuspid regurgitation. Circulation 1984, 70:657-62.

22 Metz D, Chapoutot L, Pollet E, et al. Intérêt diagnostique et prognostique du doppler continu dans l'émbolie pulet prognostique du doppler continu dans l'

23 Tiede N, Kasper W, Geibel A, Bassenge D, Langenstein B, Meinertz T, Just H. Thrombolytische Behandlung der akuten und subakuten rezidivierenden Lungenembolie mit rekombinantem Gewebe-Plasminogenaktivator. Dtsch Med Wochenschr 1990;115:
1699-704. 